\title{
Study on Phosphorus Loss \\ Characteristics and Influencing Factors of Agricultural Non-point Source Pollutants in Watershed Based on SWAT and ArcGIS
}

\author{
LIANGMIN GAO ${ }^{1}$, JINXIN ZHANG ${ }^{2}$, XIAOQING CHEN ${ }^{2}$ \\ AND HUI WANG ${ }^{2}$ \\ ${ }^{1}$ Anhui University of Science and Technology \\ ${ }^{2}$ School of Earth and Environment, Anhui University of Science \\ and Technology
}

Presenting Author: gaolmin@163.com

In order to study the characteristics of phosphorus loss from agricultural non-point source pollutants in the Shaying River Basin (a primary tributary of the Huaihe River), the characteristics of agricultural non-point source pollutant and soil loss was quantitative analyzed in the paper. Especially, combining with the SWAT, the soil erosion USLE model, geographic information technology, mathematical statistics technology was applied. Besides, influencing factors such as land use, topography, rainfall and soil type were comprehensively considered.

The SWAT model of the basin was established, and the output results of the SWAT model were calibrated and verified based on monthly volume of runoff and water quality data. The simulated and measured values of runoff and total phosphorus are in good agreement. During the Calibration, the correlation coefficient $\left(\mathrm{R}^{2}\right)$ of the runoff is 0.85 , the Nash-Sutcliffe efficiency coefficient (NSE) is 0.82 ; the $\mathrm{R}^{2}$ of the total phosphorus load is 0.64 , and the NSE is 0.61 . During the verification period, the $\mathrm{R}^{2}$ of the runoff is 0.82 , the NSE is 0.79 ; the $\mathrm{R}^{2}$ of the phosphorus load is 0.64 , and the NSE is 0.62 .

Using the USLE model and ArcGIS technology, Soil erosion amount was estimated by grid calculation based on the calculation of rainfall erosivity factor R, terrain LS, soil erodibility factor $\mathrm{K}$, vegetation cover - management factor $\mathrm{C}$ and soil -water conservation factor P. The results show that the soil erosion modulus of the township administrative unit ranges from 291 to $3568 \mathrm{t} /\left(\mathrm{km}^{2} \cdot \mathrm{a}\right)$, and the multi-year average value is 1593 $\mathrm{t} /\left(\mathrm{km}^{2} \cdot \mathrm{a}\right)$, indicating that the overall soil erosion is mild. The loss of organic phosphorus, soluble phosphorus, mineral phosphorus and total phosphorus showed an increasing trend over time, and the degree of loss showed a characteristic that the southern region was greater than that of the northern region. When the local slope gradient of the zone is $3^{\circ}-6^{\circ}$, the maximum soil erosion modulus growth rate reaches $50 \%$, which is the sensitive slope zone of soil erosion in this study area.

This research was supported by Key Research and Development Projects in Anhui Province of China (NO. 202004i07020012) 